\title{
Using Quick Response Codes with Videos in the Laboratory
}

\author{
Marina Duarte, School of Engineering, Polytechnic of Porto, Porto, Portugal \\ Andresa Baptista, School of Engineering, Polytechnic of Porto, Porto, Portugal \\ Gustavo Pinto, School of Engineering, Polytechnic of Porto, Porto, Portugal
}

\begin{abstract}
Using QR codes to access low-cost, educational, short videos in engineering laboratory classes might be a successful way of building a bridge from concrete to digital content. With QR codes placed on the apparatus, students will know exactly which video to watch. The scanned QR codes can be saved, enabling students to watch them again while performing the experiment or at home. Low-cost videos do not require expensive equipment and software, and keeping the videos short assures a minimum download time, making them compatible for use with smartphones and tablets. The aim of this research is to evaluate the importance undergraduate engineering students attribute to these videos and their reaction to the possibility of accessing them with QR codes scanned by a smartphone or a tablet. Results show students attributed some importance to the videos, and that the QR codes are very helpful as means to quickly and easily access the videos.
\end{abstract}

\section{KEYWORDS}

Educational Videos, Engineering Education, Higher Education, Laboratory, Low-Cost Videos, QR Codes, Short Videos

\section{INTRODUCTION}

Active learning in engineering is impossible without laboratories, and the recognition of their importance by engineering teachers dates back to 1980 (Fishenden \& Markland, 2006). From the earliest days of engineering education, instructional laboratories have been an essential part of study programmes (Feisel \& Rosa, 2005; Pandermarakis, Sotiropoulou, Passa, \& Mitsopoulos, 2012; Surgenor \& Firth, 2011). This is expected because the overall goal of engineering education is the preparation of students to practice engineering and because students' understanding of a domain can be enhanced when they engage in laboratory experiments (Litzinger, Lattuca, Hadgraft, \& Newstetter, 2011). In addition, many studies have emphasized the role of laboratory education in students' motivation, which is particularly important considering 'the continuous drop in student numbers taking engineering and science courses' (Abdulwahed, Nagy, \& Blanchard, 2008, p. 2).

Krivickas and Krivickas (2007) argue that engineering education is inconceivable without laboratory instruction, but the modernised laboratory presents a challenge to the academic staff in developing new and more effective instruction and facing the "many disadvantages such as constraints on time, resources, maintenance, expensive equipment, and safety hazards' (Abdulwahed et al., 2008, p. 2). 
Undoubtedly, the massification of higher education is a challenge as laboratories requiring human and material resources depend directly on the number of students. But if, as Feisel and Rosa (2005) mention, this works against a quality laboratory experience, the introduction of Information and Communications Technology (ICT) works for it.

The broad use of ICT, which can be seen as an obstacle to conventional hands-on classes in the laboratory, really is an opportunity because almost every student has the technological means to access the World Wide Web, having technology that 'walks in' classes (Gradel \& Edson, 2013). Students are used to accessing information with a click or a slide, and laboratories must keep up to date and not be restricted to the physical space of the laboratory itself.

The great majority of higher education students are what Prensky (2001) describes as digital natives because of their familiarity with and reliance on ICT. They live immersed in technology, 'surrounded by and using computers, videogames, digital music players, video cams, cell phones, and all the other toys and tools of the digital age' (Prensky, 2001, p. 1). Bennett, Maton, and Kervin (2008, p. 776) point out that 'they are held to be active experiential learners, proficient in multitasking, and dependent on communications technologies for accessing information and for interacting with others', but this might not be entirely true, as students' everyday technology practices may not be directly applicable to academic tasks. In their literature review, Halupa and Caldwell (2015) highlight the difficulty in implementing new methods and technologies in the classroom and the resistance of students to learning in a new way. Rogado et al. (2015) also report the difficulties students have in incorporating new technology in their learning.

It therefore is important that ICT is used in the laboratory with moderation and in an integrated way, blending it with hands-on experimental activities. Resorting to new and current devices and applications that students use in their everyday life and recognize as good practices (Ricoy \& Couto, 2014) might be a good way to capture their interest and increase motivation, and by doing so, improve learning.

This purpose is well served by low-cost, educational, short videos that can be used to explain operational procedures, show what is expected to happen during a certain experiment, and allow students to watch them over and over again while performing the actual experiment. As these videos can be made available in a platform like YouTube, it is important that students know exactly what video to watch when in the laboratory. That is why the possibility of accessing videos with Quick Response (QR) codes is essential to building what Gradel and Edson (2013, p. 62) designate as a 'bridge from concrete to digital content'.

The aim of this research is to evaluate the importance students attribute to low-cost, educational, short videos that explain the operating procedure of laboratory apparatus and the students' reaction to the possibility of accessing videos with QR codes by using a smartphone or a tablet.

The rest of this paper is structured as follows. The next section addresses the state of the art regarding the use of videos and QR codes in higher education. In the third section, we describe a case study. The fourth section addresses the methods used in this research while the fifth section presents the results. The final section presents a discussion of results and conclusions.

\section{VIDEOS AND QR CODES}

\section{Teaching and Learning with Videos}

Although the use of educational videos has been widely employed in past years, recently interest in their use has increased incrementally because of platforms such as YouTube (Chan, 2010; Giannakos, 2013), video-based learning systems such as Khan Academy and edX, new for-profit companies such 
as Coursera and Udacity (Giannakos, 2013) and new teaching/learning models such as flipped learning (Fulton, 2014; Observatory of Educational Innovation of the Tecnológico de Monterrey, 2014).

According to Caspi, Gorsky, and Privman (2005), educational videos can be divided into three categories: demonstration videos, narrative videos and lecture session videos. In the laboratory, demonstration videos usually are used as they are really good tools that allow and improve autonomous learning and are becoming much more effective than methodologies based on more traditional methods. Therefore, this methodology enables faculty, especially in technology-related areas, to develop new teaching and learning strategies, adding a new dimension to the teaching material.

Being able to watch a demonstration of procedures in a video, while also hearing an explanation and reading the actual procedure, is more effective than just reading about them because of the opportunity to visualize the interaction with the apparatus. In a study conducted by Goset and Espinoza (2014, p. 93), 'the results showed a clear preference for the use of the demonstrative type of videos, specifically for information transmission'. The benefit of using videos is the fact that the procedures display, reinforced with text or narrative creates a common language and shared meanings. The complexity of the oral language to explain technical activities or situations is remedied by the visual language, giving the possibility to create a meaningful and relevant common conceptual basis (Goset \& Espinoza, 2014, p. 93).

Videos have the advantage of using ... audiovisual language that is synthetic and integral. It is entirely synthetic, since it merges audio and visual to create a new communication. It is not an addition, but a merging of sound and moving image, which allows the brain to integrate, at the same time, the information that it understands and the information that visual and acoustic memories have preserved, which give the whole its meaning (Cloutier, 1975, p. 136).

Videos also offer the possibility to match learning pace with students' own needs (Caspi et al., 2005; Chan, 2010), and the increasing use of smartphones and tablets (Giannakos, 2013) make it possible to watch videos while operating the laboratory apparatus. Furthermore, students can watch the videos at home as many times as needed, taking notes, pausing, and moving backward and forward according to their own needs (De la Fuente Sánchez, Hernández Solís, \& Pra Martos, 2013). This makes learning more flexible (Montoya \& Hernández, 2016).

On the down side, students can experience some technical problems (Montoya \& Hernández, 2016), and instructors need to have the knowledge, design skills and creativity to create the videos in addition to having the appropriate hardware and software. Although this endeavour may be time consuming, a good video can be used for years and easily can be made available on YouTube, which is free, user friendly and mobile friendly (Chan, 2010). Nowadays, the 'easy creation, distribution and instantaneous uploading and downloading of digital media is the norm' (Bramhall, Radley, \& Metcalf, 2008, p. 2). It is not necessary to be an expert to make a good quality video as 'the fast development of new technologies and the decrease of costs related to video recording, editing and production, make this tool available to faculty, allowing self audiovisual creation, according to the own needs and by means of economic tools' (Fernandez et al., 2011, p. 3).

\section{Using QR Codes}

The video's purpose and audience determine how to present it and where to host it (Bolorizadeh, Brannen, Gibbs, \& Mack, 2012). In the laboratory, it is essential for students to know which videos to watch and to be able to access them not only while operating the equipment and apparatus, but also whenever it is needed. So, according to Gradel and Edson (2013, p. 62) 'field and lab work may be enhanced by connections to existing content'. Bolorizadeh et al. (2012, p. 375) found that 'students are willing to use video resources as long as the videos can be found easily, the videos are short and present the desired information quickly, and the information is accurate'.

QR codes are two-dimensional matrix codes, easy to use and to create, that can be freely generated online. They were designed in Japan by Denso Wave Inc. in 1994 to meet the increasing market 
demands of information storage capacity, character types, and print size limitations of standard bar codes (Denso Wave Incorporated, n.d.-a), and they have been widely adapted for advertising purposes.

The real value of QR code access is the speed and convenience with which the information is delivered, eliminating the need to manually key text when accessing documents, videos or an internet website (Bonifácio, 2012; Law \& So, 2010; Lombardo, Morrow, \& Le Ber, 2012). To read QR codes, mobile devices need a camera and a scanning application. If the content being accessed is online, a connection to the internet also is required.

When using QR codes, users' scanning history is saved in their QR readers, just as with internet browsers. This redundancy may hold a special valence for educational purposes because, once scanned, resources accessed by QR codes become immediately 'clickable' in the students' mobile devices (Gradel \& Edson, 2013).

There are two kinds of QR codes: static and dynamic. Dynamic QR codes are preferable because it is possible to update the content without changing the address since the codes are an online service that redirects the user to the new content. Even if the content changes, the URL remains the same and reprinting of the code is not necessary. The online management of a dynamic QR code also makes it possible to retrieve statistics from the code's usage.

This is not the case for static QR codes that point to a certain address. If the information is changed (for example, a new version of a video is uploaded to YouTube), it is likely that a new address is created, which means that a new static QR code is needed.

Nevertheless, the use of a free, online, dynamic QR code service is not without risks, as Lombardo et al. (2012, p. 22) point out, because 'relying on free services, based somewhere out on the Internet, creates the risk that the service can increase the pricing, or disappear altogether'. So a paid service might be a good investment.

In education, the use of QR codes is still in its infancy (Law \& So, 2010), but with 'usage across both P-12 and higher education settings' (Gradel \& Edson, 2013, p. 50):

The low technical barrier of creating and reading QR codes allows innovative educators to incorporate them into their educational endeavours. The operations to retrieve or store QR codes are incredibly simple and quick, and with mobile devices, make them the ideal educational tools for teaching and learning. (Law \& So, 2010, p. 85)

Many research studies focus on the usefulness of QR codes because 'any new technology needs to be perceived as being useful in order for it to be accepted and assimilated into people's daily routines' (Shin, Jung, \& Chang, 2012, p. 1417). The settings for much of this research are undergraduate classrooms, libraries, and museums (Traser, Hoffman, Seifert, \& Wilson, 2015) but not engineering education.

\section{CASE STUDY}

\section{Context}

The current study was conducted in the School of Engineering of Polytechnic of Porto, in Portugal. Founded in 1852, the school has more than 6,000 students and 500 faculty and staff members, organized in departments that are responsible for 12 Bachelor of Science and 11 Master of Science degrees. As a polytechnic school, the emphasis is on students learning how to apply knowledge to become agents of global progress. This tradition of applied knowledge and research is grounded in a large number of laboratories and technical staff, enabling students to have a hands-on approach to learning.

The research took place in the Heat and Fluids Laboratory (H\&F Lab). This lab is one of the laboratories of the Department of Mechanical Engineering, which is attended mainly by students earning a Bachelor of Science degree in mechanical engineering or civil engineering. 
The H\&F Lab has 339 square meters, with several apparatus and instruments in hydraulics, fluid mechanics, thermodynamics, heat transfer, turbomachinery and refrigeration. To help students better use the equipment and understand underlying concepts, the laboratory has made available manuals and written operational procedures.

\section{Videos in the H\&F Lab}

In the H\&F Lab there are written operational procedures for all the apparatus and experiments. Although these procedures are well illustrated, videos make many details more understandable because they present motion. Using written procedures as a starting point, we planned to create two low-cost, educational videos: one regarding an operational procedure that uses several apparatus and another featuring an operational procedure using a particular apparatus. The educational purpose of the videos was to complement a teacher's live explanation of the operational procedures, namely by including (a) a brief explanation of the main features of the apparatus, (b) safety instructions, (c) how to operate the apparatus and its instrumentation and (d) what to measure and how to measure it. The videos were not associated with any particular course or programme.

The low-cost option relates to the ease with which this methodology can be applied in other contexts. Fernandez et al. (2011, p. 3) define low-cost educational video 'as a short demonstration stream video which has a very specific goal and has been created in a very short period of time, with few resources and that can be combined or embedded within other materials of a course'. The creation of these kind of videos implies, according to Simo et al. (2010, p. 2939), 'finding ways to produce and distribute audiovisual teaching equipment minimizing the costs (...) both in terms of physical resources and economic, as in actual time spent by faculty in the design and creation of audiovisual material'.

The choice was made to create mini-videos, defined as 'short videos that constitute a technological educational resource to convey a particular information that will help to consolidate a certain learning' (De la Fuente Sánchez et al., 2013, p. 180). Hsin and Cigas (2013) recommend using short videos as a way to address several issues presented by long videos such as the difficulty in maintaining students' attention and the problem of a lengthy file download. Some authors (De la Fuente Sánchez et al., 2013; Hsin \& Cigas, 2013; Sexton, 2006) report the use of videos under 5 minutes.

For the videos in the H\&F Lab, the intention was for students to be able to download them with smartphones or tablets, which would be easier with very short videos. Because of that, the published videos were 1:51 minutes and 1:38 minutes long, respectively. Although this implied that the action taking place on the video would happen at a relatively fast pace, this possible limitation could be overcome by students stopping the video or rewinding it.

In the making of these short videos, planning was very important to ensure that the educational purpose of the videos was met. Resorting to the plan-shoot/capture-edit-deliver methodology (Bolorizadeh et al., 2012), the making of the videos comprised the following steps.

First was development of the plan: The team chose two written operational procedures as the subject for the videos. These procedures were used to write the storyboard and the script, and the location was checked for light and sound conditions. We installed free or common license software for the editing of film, images and audio; the software included a video editor, an audio editor, an image and photo editor and a presentations editor. (Free versions of software tend to include only a portion of the features available in the paid version of the software, which often is enough as long as the essential features are maintained. This simplifies its use and does not require advanced levels of computing.)

The second step was shoot/capture. The team checked all equipment, using a standard digital camera to capture film and photos and a microphone to capture the audio. We made image and audio tests in the location, and captured image and audio using different plans (zoom in and zoom out). Finally, we checked the image and audio quality before finishing the shooting session. 
The third stage was the editing. The team downloaded all film and photos, editing them for better quality and to match the script and storyboard. We included text whenever it improved comprehension of the video content. Using the video, we adjusted the script, and rehearsed and recorded the narration to ensure synchronization. The team added narration, maintaining the location's audio whenever it was needed. Next, the team obtained feedback and included the suggestions in the final version, adding finishing elements before having experts in this scientific/technical field validate the content and accuracy of the information conveyed by final version of the videos.

The final stage was delivering the videos. We chose to host the videos on the YouTube platform and selected the appropriate quality/size for publishing the video. The team created links and others necessary access features for the video, testing them with several smartphones and tablets.

\section{QR Codes in the H\&F Lab}

To overcome the difficulty of accessing the virtual world in the real world environment of the H\&F $\mathrm{Lab}$, the videos were linked to QR codes. We made a thorough search of free editors (online and offline) of dynamic QR codes and found a free online website. This website also provides access statistics and has no limit for the number of codes generated. These dynamic QR codes are black and white, black representing foreground squares and white representing background squares. The number of modules is $29 \times 29$ (version 3), which allows the storage of 32-127 characters, depending on the type of information (Denso Wave Incorporated, n.d.-b). This was enough for each video link.

QR codes include redundant information with the purpose of making corrections possible. So, even if damaged, this redundant data ensures the readability of QR codes. The correction level of data in the free dynamic QR codes generated online is 30\% (The Marketing Bureau UK Ltd, n. d.), and the three pattern-detection squares on the corners allows the scanning of the code in any direction (omnidirectional).

The team conducted tests with several smartphones and tablets in a multitude of circumstances to ensure that these technical features were appropriate and that the codes worked in less than perfect conditions. Because there are a number of free apps available to scan QR codes, we downloaded and tested several, choosing the ones with higher ratings. All the apps were adequate.

We printed the QR codes (testing the appropriate size) and made them available on the apparatus and on information boards in the H\&F Lab. All the students participating in the study were told how they could access the videos using their smartphones and tablets and how to save this information for further use. Almost all the students had the technological means to access the videos it, which was expected because in Portugal $46.4 \%$ of cell phones bought in 2012 were smartphones. For people 15-24 years of age, this value was $60 \%$ above average. These numbers represent an increase in smartphone use of $80 \%$ since May 2012 (Gaspar, 2014).

\section{METHOD}

\section{Participants}

The participants were 41 students (36.6\% female and $63.4 \%$ male) studying to earn a bachelor of science degree in civil engineering in the School of Engineering of Polytechnic of Porto. This was a convenience sample that represented $57 \%$ of the students attending the H\&F Lab (72 students). All participants collaborated voluntarily with this research.

The participants ranged in age from 19 to $66(M=27.59, S D=9.439)$; 34 participants $(82.9 \%)$ were Portuguese and seven (17.1\%) were different nationalities. In addition, 32 (78.0\%) were secondyear students and seven (17.1\%) were third-year students (4.9\% were missing values), and $29(70.7 \%)$ attended classes during the day, while nine $(22.0 \%)$ did so at night ( $7.3 \%$ were missing values). 


\section{Instruments}

To evaluate the importance of educational videos as pedagogical resources, we used an adapted version of the VINCERE questionnaire (FEUP-LEA, n. d.). Responses on the survey were measured using a 7-point Likert scale, where 1 is unimportant and 7 is full importance. The items are aggregated in three dimensions: ease and motivation, appropriateness to the contents and objectives and role in the evaluation. Three of the original 12 items were not used because they did not apply, and a new item was included because of the type of videos used. This adapted questionnaire had 10 items for a maximum of 70 points.

Some additional questions were included, namely regarding audio and image quality of the videos, and the importance of accessing them with QR codes. Participants also were asked to comment on the strengths and weakness of the videos.

A socio-demographic and academic questionnaire was used to characterise the participants, including such items as age, nationality, gender, course of studies, curricular year and class attendance schedule.

\section{Procedure}

Participants were approached during classes (with the permission and cooperation of their teachers) in December 2014 and asked to complete a paper-and-pen questionnaire. Participation was voluntary. The data were collected after the participants had attended practical classes in the H\&F Lab.

The validity and reliability of the VINCERE questionnaire then was assessed. To measure the validity of the scale, we evaluated the adequacy of data for exploratory factor analysis using the Kaiser-Meyer-Oklin criteria and Bartlett's test of sphericity. The sample size was adequate with a Kaiser-Meyer-Oklin value of 0.773 and Bartlett's test of sphericity $\left(\chi^{2}(21)=117.412, p=0.000\right)$ was statistically significant as required. These results allowed exploratory factor analysis with the principal components analysis extraction method and varimax rotation. Factors with an eigenvalue greater than 1 were retained. The indicator of the scale's reliability was internal consistency, and Cronbach's alpha was performed.

Content analysis was used for the participants' comments on the strengths and weaknesses of the videos, using emergent categories.

\section{RESULTS}

The 10-item VINCERE questionnaire first was subjected to exploratory factor analysis (principal components analysis extraction method; varimax rotation) in SPSS 21.0. Three items (items 1, 3 and 5) were dropped, and two factors were identified. Factor 1 (appropriateness to the contents and objectives) was comprised of items 2, 4, 7 and 9 and explained $44.7 \%$ of the variance. Factor 2 (ease and motivation) was comprised of items 6,8 and 10 and explained the remaining $30.6 \%$ of the variance. Table 1 presents the factor loadings.

Communalities ranged from 0.471 to 0.838 . The alpha levels were good, being 0.830 for the total scale, 0.864 for Factor 1 (appropriateness to the contents and objectives) and 0.763 for Factor 2 (ease and motivation).

Table 2 includes descriptive statistics such as means, standard deviations and standard errors for the importance students attributed to the videos (total of VINCERE scale; maximum 49 points) and for its factors (maximum 28 points for Factor 1 and 21 points for Factor 2). The overall score was 57\%, with 36\% for Factor 1 and 21\% for Factor 2.

The item that scored lower on average $(M=3.41)$ was related to not using other information sources because of the videos. The item that scored higher on average $(M=4.81)$ was related to the video being a clear example of what was intended to demonstrate. 
Table 1. Results of the factor analysis

\begin{tabular}{|l|l|l|}
\hline \multirow{2}{*}{ Scale Items } & \multicolumn{2}{|c|}{ Factor Loading } \\
\cline { 2 - 4 } & \multicolumn{1}{|c|}{ Factor 1 } & \multicolumn{1}{c|}{ Factor 2 } \\
\hline 2 & 0.887 & --- \\
\hline 4 & 0.876 & -- \\
\hline 7 & 0.830 & -- \\
\hline 9 & 0.867 & 0.636 \\
\hline 6 & -- & 0.876 \\
\hline 8 & -- & 0.914 \\
\hline 10 & -- & \\
\hline
\end{tabular}

Table 2. VINCERE scale descriptive statistics

\begin{tabular}{|l|l|l|l|l|}
\hline \multicolumn{1}{|c|}{ Factors } & \multicolumn{1}{|c|}{$\boldsymbol{N}$} & \multicolumn{1}{c|}{$\boldsymbol{M}$} & \multicolumn{1}{c|}{$\boldsymbol{S D}$} & \multicolumn{1}{c|}{$\boldsymbol{S E}$} \\
\hline Appropriateness to the contents and objectives & 32 & 17.69 & 4.915 & 0.869 \\
\hline Ease and motivation & 32 & 10.41 & 3.934 & 0.695 \\
\hline Total VINCERE: Importance of the videos & 32 & 28.09 & 7.346 & 1.299 \\
\hline
\end{tabular}

On average, the audio and video quality was considered good; no participant found it bad while others considered it very good.

The videos were viewed 1.54 times on average (most participants watched them once; $25 \%$ of participants watched them two or more times to a maximum of five times.

When questioned about the importance of being able to access the videos with QR codes in the laboratory, the average score was 4.53 , with the $75 \%$ quartile scoring 6.75 (the highest of all items).

Participants' comments on the strengths of the videos included the quickness of being able to access information about the experimental procedure, the ease in accessing information and the clarity of the explanation given. Regarding the weaknesses, participants mentioned some difficulty in the first viewing, the videos being too fast and the explanation given not being enough. Participants also referred to the unavailability of more videos as a weakness.

Some confusion seemed to exist, with students thinking the videos were related to a particular course or teacher and not understanding why the videos were not available as resources for the courses. They had trouble understanding that it was the H\&F Lab that created the videos and made them available, regardless of courses and study programmes.

\section{DISCUSSION AND CONCLUSION}

Laboratories are of paramount importance for engineering education, but traditional hands-on classes face several challenges, which also can be seen as opportunities. Having students connected to the digital world, bringing to the classroom their own devices, widens the educational possibilities.

With that in mind, two low-cost, educational short videos that explained operational procedures were created and made available in the H\&F Lab through the use of QR codes. The aim of the research was to evaluate the importance students attribute to these instructional videos and their reaction to the possibility of accessing them with QR codes. 
As the videos were created with free software by the laboratory staff, not multimedia experts, it was important to assess the quality of the final product. Students found them good or very good, showing that is possible, with modest means and some creativity, to make appropriate educational short videos.

The fact that these videos present very technical procedures and explanations might account for the fact that ease and motivation scored lower than appropriateness to the contents and objectives.

Students attributed only some importance to the videos (the overall score of VINCERE questionnaire were 57\%), which was expected, as only two very short videos were available.

The videos complemented other educational resources provided by the course teachers, and it was never intended to use them as substitutes. This explains why the item that was related to not using other information sources because of the videos scored lower on average.

The clarity of the explanation provided, which is fundamental in instructional videos of operational procedures, was rewarded by the students with the highest score and the demand for more videos. Other positive aspects were the quickness and ease of accessing information, showing that the QR codes are a helpful solution in the laboratory.

In conclusion, students attribute some importance to the videos, and the QR codes in the laboratory were well received by the students who considered by them very helpful as a means to access the videos. 


\section{REFERENCES}

Abdulwahed, M., Nagy, Z. K., \& Blanchard, R. (2008). The tri lab, a novel view of laboratory education. Proceedings of the EE2008 - International conference on innovation, good practice and research in engineering education. Loughborough: HEA Engineering Subject Centre.

Bennett, S., Maton, K., \& Kervin, L. (2008). The digital natives debate: A critical review of the evidence. British Journal of Educational Technology, 39(5), 775-786. doi:10.1111/j.1467-8535.2007.00793.x

Bolorizadeh, A., Brannen, M., Gibbs, R., \& Mack, T. (2012). Making instruction mobile. The Reference Librarian, 53(4), 373-383. doi:10.1080/02763877.2012.707488

Bonifácio, V. D. B. (2012). QR-coded audio periodic table of the elements: A mobile-learning tool. Journal of Chemical Education, 89(4), 552-554. doi:10.1021/ed200541e

Bramhall, M., Radley, K., \& Metcalf, J. (2008). Users as producers: Students using video to develop learner autonomy.Proceedings of the EE2008 - International conference on innovation, good practice and research in engineering education. Loughborough: HEA Engineering Subject Centre.

Caspi, A., Gorsky, P., \& Privman, M. (2005). Viewing comprehension: Students learning preferences and strategies when studying from video. Instructional Science, 33(1), 31-47. doi:10.1007/s11251-004-2576-X

Chan, Y. M. (2010). Video instructions as support for beyond classroom learning. Procedia: Social and Behavioral Sciences, 9, 1313-1318. doi:10.1016/j.sbspro.2010.12.326

Cloutier, J. (1975). A era de Emerec ou a comunicação audio-scripto-visual na era dos self-media [The age of EMEREC or the audio-script-visual communication in the era of self-media]. Ministério da Educação e Investigação Científica - Instituto de tecnologia Educativa.

De la Fuente Sánchez, D., Hernández Solís, M., \& Pra Martos, I. (2013). El mini video como recurso didáctico na aprendizagem de materias cuantitativas[Mini videos as didactic resources in quantitative subjects]. Revista Iberoamericana de Educación a Distancia, 16(2), 177-192. doi:10.5944/ried.16.2.9911

Denso Wave Incorporated. (n. d.a). Answers to your questions about the QR code. Retrieved from http://www. qrcode.com/en/

Denso Wave Incorporated. (n. d.b). Information capacity and versions of the QR code. Retrieved from http:// www.qrcode.com/en/

edutrendsaprendizajeinvertido

Feisel, L. D., \& Rosa, A. J. (2005). The role of the laboratory in undergraduate engineering education. The Journal of Engineering Education, 94(1), 121-130. doi:10.1002/j.2168-9830.2005.tb00833.x

Fernandez, V., Simo, P., Ines, A., Albareda-Sambola, M., Nuria, S., Amante, B., \& Federico, G. et al. (2011). 'Low-cost educational videos' for engineering students: A new concept based on video stream and Youtube channels. International Journal of Engineering Education, 27(3), 1-10.

FEUP-LEA. (n. d.). Vincere: Ciências e engenharia em português [Vincere: Science and engineering in Portuguese]. Retrieved from https://paginas.fe.up.pt/ lea/projvincere/

Fishenden, C., \& Markland, E. (2006). A systems approach to elementary laboratory instruction. European Journal of Engineering Education, 4(3-4), 293-302. doi:10.1080/0304379800040306

Fulton, K. P. (2014). Time for learning: Top 10 Reasons why flipping the classroom can change education. Thousand Oaks, CA: Corwin Press.

Gaspar, A. (2014). Metade da população portuguesa já utiliza smartphones [Half of the Portuguese population uses smartphones]. Jornal de Notícias. Retrieved from http://www.jn.pt/PaginaInicial/Tecnologia/Interior. aspx?content_id=4114579

Giannakos, M. N. (2013). Exploring the video-based learning research: A review of the literature. British Journal of Educational Technology, 44(6), E191-E195. doi:10.1111/bjet.12070 
Goset, J., \& Espinoza, P. (2014). Perception of the use of teaching videos in preclinical training of Chilean dentistry students, 2013. Journal Of Oral Research, 3(2), 90-94. doi:10.17126/joralres.2014.022

Gradel, K., \& Edson, A. J. (2013). QR codes in higher ed: Fad or functional tool? Journal of Educational Technology Systems, 41(1), 45-67. doi:10.2190/ET.41.1.e

Halupa, C. M., \& Caldwell, B. W. (2015). A Comparison of two engineering statics courses: Traditional lecturebased and lecture-based with online supplemental video. International Journal of Higher Education, 4(1), 232-240. doi:10.5430/ijhe.v4n1p232

Hsin, W.-J., \& Cigas, J. (2013). Short videos improve student learning in online education. Journal of Computing Sciences in Colleges, 28(5), 253-259.

Krivickas, R. V., \& Krivickas, J. (2007). Laboratory instruction in engineering education. Global Journal of Engineering. Education, 11(2), 191-196.

Law, C., \& So, S. (2010). QR codes in education. Journal of Educational Technology Development and Exchange, $3(1), 85-100$.

Litzinger, T., Lattuca, L. R., Hadgraft, R., \& Newstetter, W. (2011). Engineering education and the development of expertise. The Journal of Engineering Education, 100(1), 123-150. doi:10.1002/j.2168-9830.2011.tb00006.x

Lombardo, N. T., Morrow, A., \& Le Ber, J. (2012). Rethinking mobile delivery: Using quick response codes to access information at the point of need. Medical Reference Services Quarterly, 31(1), 14-24. doi:10.1080/027 63869.2012.641817 PMID:22289092

Montoya, M. S. R., \& Hernández, D. (2016). Inverted learning environments with technology, innovation and flexibility. Journal of Information Technology Research, 9(1), 18-33. doi:10.4018/JITR.2016010102

Observatory of Educational Innovation of the Tecnológico de Monterrey. (2014). Flipped learning. Monterrey. Retrieved from http://observatorio.itesm.mx/

Pandermarakis, Z. G., Sotiropoulou, A. B., Passa, D. S., \& Mitsopoulos, G. D. (2012). The role of engineering educational laboratories at a thesis level. SEFI (European Society for Engineering Education) 40th Annual Conference Proceedings.

Prensky, M. (2001). Digital natives, digital immigrants part 1. On the Horizon, 9(5), 1-6. doi:10.1108/10748120110424816

Ricoy, M. C., \& Couto, M. (2014). As boas práticas com TIC e a utilidade atribuída pelos alunos recém-integrados à universidade [Good practices with ICT and the use attributed by higher education freshmen]. Educação E Pesquisa, 40(4), 897-912.

Rogado, A. B. G., Quintana, A. M. V., Conde, M. J. R., Martín, I. R., Abad, F. M., Miguelañez, S. O., \& Diego, P. B. (2015, March 11). Adquisición de la competencia de prevención de riesgos en el laboratorio mediante tecnología móvil. Revista del Congrés Internacional de Docència Universitària i Innovació (CIDUI). Retrieved from http://www.cidui.org/revistacidui/index.php/cidui/article/view/663

Sexton, R. L. (2006). Using short movie and television clips in the economics principles class. The Journal of Economic Education, 37(4), 406-417. doi:10.3200/JECE.37.4.406-417

Shin, D.-H., Jung, J., \& Chang, B.-H. (2012). The psychology behind QR codes: User experience perspective. Computers in Human Behavior, 28(4), 1417-1426. doi:10.1016/j.chb.2012.03.004

Simo, P., Fernandez, V., Algaba, I., Salan, N., Enache, M., Albareda-Sambola, M., \& Rajadell, M. et al. (2010). Video stream and teaching channels: Quantitative analysis of the use of low-cost educational videos on the web. Procedia: Social and Behavioral Sciences, 2(2), 2937-2941. doi:10.1016/j.sbspro.2010.03.444

Surgenor, B., \& Firth, K. (2011). The role of the laboratory in design engineering education.Proceedings of the 2nd Canadian Engineering Education Association.

The Marketing Bureau UK Ltd. (n. d.). FAQs. Retrieved from http://www.freeqrcodetracker.com/pages/faqs

Traser, C. J., Hoffman, L. A., Seifert, M. F., \& Wilson, A. B. (2015). Investigating the use of quick response codes in the gross anatomy laboratory. Anatomical Sciences Education, 8(5), 421-429. doi:10.1002/ase.1499 PMID:25288343 